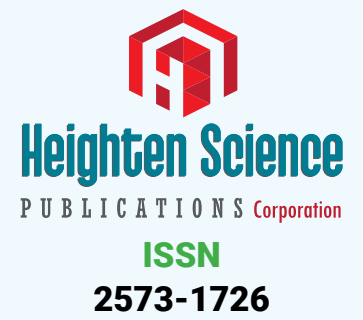

*Address for Correspondence: Dr. Manan Vora, Abhinav Bindra Targeting Performance, Mohali, India, Tel: +91 9819617727; Email: mananuvora@gmail.com

Submitted: 02 October 2018

Approved: 18 October 2018

Published: 19 October 2018

Copyright: (C) 2018 Vora M, et al. This is an open access article distributed under the Creative Commons Attribution License, which permits unrestricted use, distribution, and reproduction in any medium, provided the original work is properly cited

Keywords: Biological age, Females, Physical activity

Check for updates
Research Article

\section{Analysis of static, dynamic, and pelvic stability in junior badminton players of South Asia}

\author{
Manan Vora ${ }^{1,3^{*}}$, Digpal Ranawat ${ }^{1,2}$, Apoorva Tiwari ${ }^{2}$ and Manit \\ Arora $^{1,3}$
}

\author{
${ }^{1}$ Abhinav Bindra Targeting Performance, Mohali, India \\ ${ }^{2}$ Abhinav Bindra Targeting Performance, Bangalore, India \\ ${ }^{3}$ Fortis Hospital, Mohali, India
}

\section{Summary}

Badminton is a sport that requires a player to perform while being still, as well as in motion. Stability is the ability to maintain or control joint movement or joint position, in the static as well as dynamic state. Improvement in stability could help maintain body control and proper posture positions during play. Accordingly, the study was proposed to analyze stability in junior badminton players and understand its importance. A total of 106 players from South Asia between the ages of 8 and 15 years were analyzed. Prokin 252N and Balance trunk MF systems of Tecnobody Italy were used in the assessment and static, dynamic, and pelvic stability was recorded. The variables used were gender, age, body mass index, and experience in years, level at which they play, current pain, and clicks \& catches in the past 1 year. Our study showed that there was significant difference in pelvic stability in terms of age and level at which players compete. There were a variety of other factors which do not affect stability. There needs to be a greater focus on stability training as part of the development of junior badminton players.

\section{Introduction}

Badminton was likely to have originated in India towards the end of the nineteenth century during British colonial rule and was played at military bases in Madras, Bombay, Peshawar, Calcutta and Poona [1]. Competitive badminton is ranked as one of the world's fastest racquet sports [2]. The demands of the sport requires a combination of good technical skills, intelligent game tactics, specific levels of fitness, and thorough psychological preparation to succeed at the international level [3].

Despite knowing the importance of biomechanics in badminton, there has been little work done on the biomechanics of badminton players. Some studies have been done on the biomechanics of clear badminton strokes [4], power strokes [5], underarm stroke, court movement, and flexibility [6], and of the badminton forehand smash technology [7]. In addition to these studies, one study investigated the role of the wrist in power generation [8].

Despite the vast literature available on Badminton, stability in Badminton has not been analysed in detail. The only important study done on balance in badminton dealt with core stability and dynamic balance in detail and found that eight weeks of core stability training improved lower limb dynamic balance and smash stroke performance in badminton players [9]. 
Apart from the studies based on biomechanics in badminton, several authors have studied various aspects of the game such as EMG activity during badminton strokes $[10,11]$, tests to determine on-court aerobic and anaerobic performance [12], and analysis leg muscle strength in male badminton players [13]. Physiologic demands and characteristics of badminton match play have been well documented [14-16].

Epidemiology of injuries in badminton has been studied extensively. The most common injuries are soft tissue sprains/strains [17], knee injuries, back injuries [18], cramps, blisters, tennis elbow [19], shoulder pain [20], Achilles tendinitis [21], and joint, ligament, and muscle injuries [22].

The purpose of this study was to assess static, dynamic and pelvic stability in junior professional badminton players and understand its importance. Balance is defined as 'the ability to maintain a base support with minimal movement and dynamically to perform a motor task while maintaining a stable position' [23]. It is the ability to maintain dynamic integration of interior and exterior forces during motor action tasks [23]. Balance is usually considered a static process, but in fact is a comprehensive, dynamic three-dimensional process containing multiple neural pathways [24].

Badminton is one of the fastest growing sports in South Asia. In the last decade, some South Asian players have consistently ranked among the top 10 players in the world and won medals at the Olympic Games, Asian Games, Commonwealth Games and BWF World Championships. Hence, a study conducted on the junior and upcoming badminton players in South Asia will enable us to assess the stability of top athletes in this age group.

\section{Methodology}

106 junior badminton players under the aegis of Badminton Association of India (BAI) were recruited for the study. Informed consent from the players, legal guardians and coaches was taken prior to participation. Approval from the BAI was taken prior to initiation of the study. All players were screened using a combination of a questionnaire and machine analysis.

The questionnaire consisted of a self-developed item set with focus on demographics, injury history, treatment history, playing career history and current injury state. The demographic data included age, sex, height, weight, and dominant hand. The injury history included questions regarding injuries in the past, their severity, whether they occurred during competition, training or daily activity, whether it prevented the player from taking part in a competition and/or training and/or daily activity, and if the pain was more during a particular badminton stroke. The treatment history questioned the form of treatment taken for the injuries, whether it was oral medication, physiotherapy, surgery, or any other. Playing career history included information regarding the age at which the player began playing badminton, whether the player has a dedicated coach and/or trainer, age at which he/she began playing badminton tournaments, and current professional level. Current injury state involved questions regarding any current pain faced by the player, and whether the player has experienced any clicks, cracks or catches in the body in the last 12 months.

The machine analysis was done by conducting a biomechanical assessment of stability. Prokin $252 \mathrm{~N}$ system of Tecnobody Italy (Figure 1) was used to assess static and dynamic stability. It is equipped with four load cells and a trunk sensor for complete and accurate stability assessment. For static stability, Stabilometric Test was performed (Figure 3) and Ellipse area was recorded. For dynamic stability, Balance Both Feet Test was performed and Total Stability Index was recorded. Balance trunk MF system of Tecnobody Italy (Figure 2) was used for pelvic stability. It is a very sensitive multi-axial platform which is able to detect the movements of the pelvis in anterior-posterior and right-left directions. Proprioceptive Compared Test was performed (Figure 4) in which quality and quantity of pelvic movement perception was traced in clockwise and anti-clockwise direction and Average Tracing Error was recorded. All the tests were done using the Tecnobody machines in Abhinav Bindra Targeting Performance at Padukone-Dravid Centre for Sports Excellence in Bangalore. 



Figure 2: Balance trunk MF system of Tecnobody Italy.



Figure 3: Athlete using the Prokin 252N system for assessment of Static and Dynamic stability.

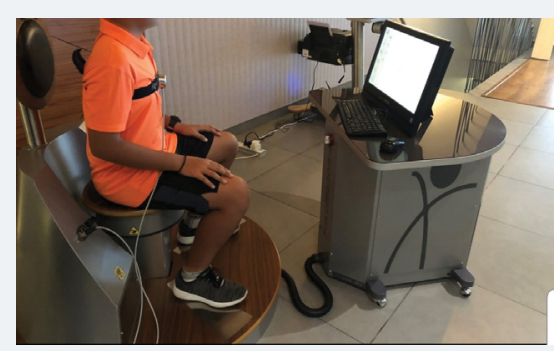

Figure 4: Athlete using the Balance Trunk MF system for assessment of Pelvic Stability.

The data was categorized into variables (Tables 1-4) and the resulting categorical data was analyzed by computing the Mean, Standard Deviation and T-test to identify the level significance in kinematic variables (Ellipse area, Total stability Index \& Average Tracing Error) using Microsoft Excel and SPSS (16.0) software. Tecnobody machines have an in-built scale that categorises the athlete into either 'poor', 'normal', or 'sportsperson' depending on the result of their assessment. Each athlete is categorised based on his/her age, height and weight to find the percentage of athletes having 'poor', 'normal' or 'sportsperson-like' stability. 


\begin{tabular}{|c|c|c|c|c|}
\hline VARIABLE S & GROUPS & $\mathbf{N}$ & MEAN \pm SD & 'P' \\
\hline \multirow{2}{*}{ GENDER } & MALE & 64 & $225.06 \pm 223.16$ & \multirow{2}{*}{0.47} \\
\hline & FEMALE & 42 & $224.22 \pm 147.87$ & \\
\hline \multirow{2}{*}{$\begin{array}{c}\text { AGE } \\
\text { (IN YEARS) }\end{array}$} & $<12$ & 41 & $199.21 \pm 112.81$ & \multirow{2}{*}{0.18} \\
\hline & $>12$ & 65 & $240.82 \pm 233.23$ & \\
\hline \multirow{2}{*}{$\begin{array}{c}\text { BMI } \\
\text { (IN KG/M2) }\end{array}$} & $<18$ & 45 & $219.89 \pm 115.62$ & \multirow{2}{*}{0.12} \\
\hline & $>18$ & 58 & $232.36 \pm 244.80$ & \\
\hline \multirow{2}{*}{$\begin{array}{l}\text { EXPERIENCE } \\
\text { (IN YEARS) }\end{array}$} & $<5$ & 49 & $227.76 \pm 166.61$ & \multirow{2}{*}{0.95} \\
\hline & $>5$ & 57 & $222.11 \pm 219.61$ & \\
\hline \multirow{2}{*}{ LEVEL } & AMATEUR & 39 & $200.31 \pm 13331$ & \multirow{2}{*}{0.21} \\
\hline & PROFESSIONAL & 67 & $238.93 \pm 224.35$ & \\
\hline \multirow{2}{*}{ CURRENT PAIN } & YES & 26 & $221.73 \pm 234.21$ & \multirow{2}{*}{0.71} \\
\hline & NO & 80 & $225.70 \pm 183.58$ & \\
\hline \multirow{2}{*}{ CLICKS \& CATCHES IN PAST 1 YR } & YES & 25 & $218.90 \pm 238.37$ & \multirow{2}{*}{0.70} \\
\hline & NO & 81 & $226.71 \pm 182.65$ & \\
\hline
\end{tabular}

Table 2: Total Stability Index in degrees.

\begin{tabular}{|c|c|c|c|c|}
\hline VARIABLES & GROUPS & N & MEAN \pm SD & 'P' \\
\hline \multirow{yyyyn}{*}{ GENDER } & MALE & 64 & $1.41 \pm 0.84$ & \multirow{2}{*}{0.86} \\
\cline { 1 - 4 }$\left(\begin{array}{c}\text { AGE } \\
\text { (IN YEARS) }\end{array}\right.$ & FEMALE & 42 & $1.23 \pm 0.82$ & \\
\hline BMI & $<12$ & 25 & $1.33 \pm 0.81$ & \multirow{2}{*}{0.83} \\
\hline (IN KG/M2) & $>12$ & 81 & $1.34 \pm 0.85$ & \\
\hline EXPERIENCE & $<18$ & 45 & $1.33 \pm 0.82$ & \multirow{2}{*}{0.98} \\
\hline (IN YEARS) & $>18$ & 58 & $1.36 \pm 0.86$ & \multirow{2}{*}{0.55} \\
\hline \multirow{2}{*}{ LEVEL } & $<5$ & 49 & $1.27 \pm 0.84$ & \multirow{2}{*}{0.30} \\
\hline \multirow{2}{*}{ CURRENT PAIN } & $>5$ & 57 & $1.39 \pm 0.83$ & \multirow{2}{*}{0.62} \\
\hline \multirow{2}{*}{ CLICKS \& CATCHES IN PAST 1 YR } & AMATEUR & 39 & $1.28 \pm 0.79$ & \multirow{2}{*}{0.76} \\
\hline
\end{tabular}

Table 3: Anticlockwise tracing error in \%.

\begin{tabular}{|c|c|c|c|c|}
\hline VARIABLES & GROUPS & $\mathbf{N}$ & MEAN \pm SD & 'P' \\
\hline \multirow{2}{*}{ GENDER } & MALE & 64 & $30.08 \pm 12.58$ & \multirow{2}{*}{0.55} \\
\hline & FEMALE & 42 & $32.21 \pm 13.20$ & \\
\hline \multirow{2}{*}{$\begin{array}{c}\text { AGE } \\
\text { (IN YEARS) }\end{array}$} & $<12$ & 25 & $38.58 \pm 14.89$ & \multirow{2}{*}{$0.03^{*}$} \\
\hline & $>12$ & 81 & $28.56 \pm 11.18$ & \\
\hline \multirow{2}{*}{$\begin{array}{c}\text { BMI } \\
\text { (IN KG/M2) }\end{array}$} & $<18$ & 45 & $32.24 \pm 12.17$ & \multirow{2}{*}{0.59} \\
\hline & $>18$ & 58 & $29.87 \pm 13.44$ & \\
\hline \multirow{2}{*}{$\begin{array}{c}\text { EXPERIENCE } \\
\text { (IN YEARS) }\end{array}$} & $<5$ & 49 & $30.19 \pm 11.87$ & \multirow{2}{*}{0.48} \\
\hline & $>5$ & 57 & $31.56 \pm 13.64$ & \\
\hline \multirow{2}{*}{ LEVEL } & AMATEUR & 39 & $33.94 \pm 14.06$ & \multirow{2}{*}{0.19} \\
\hline & PROFESSIONAL & 67 & $29.17 \pm 11.78$ & \\
\hline \multirow{2}{*}{ CURRENT PAIN } & YES & 26 & $31.35 \pm 14.01$ & \multirow{2}{*}{0.61} \\
\hline & NO & 80 & $30.79 \pm 12.48$ & \\
\hline \multirow{2}{*}{ CLICKS \& CATCHES IN PAST 1 YR } & YES & 25 & $31.32 \pm 14.31$ & \multirow{2}{*}{0.43} \\
\hline & NO & 81 & $30.80 \pm 12.41$ & \\
\hline
\end{tabular}

As seen in Table 3, there is a significant difference in Anti-clockwise tracing error between badminton players aged below and above 12 .

*significant difference level at (0.05)

\section{Results}

A total of 106 junior South Asian Badminton players underwent the assessment. Out of the 106 players, 62 were male players and 44 were female players. 96 of them were from India, 4 each from Nepal and Sri Lanka, while 2 players were from Maldives. The age group was between 8 and 15 years. The data is presented in table 1, 2, 3 and 4 .

Table 1 shows difference in ellipse area while Table 2 shows difference in total stability index between various groups. Gender, age, BMI, experience in years, level at which they play, current pain, and clicks \& catches in the past 1 year were the variables. 


\begin{tabular}{|c|c|c|c|c|}
\hline VARIABLES & GROUPS & $\mathbf{N}$ & MEAN \pm SD & 'P' \\
\hline \multirow{2}{*}{ GENDER } & MALE & 64 & $26.98 \pm 12.83$ & \multirow{2}{*}{0.75} \\
\hline & FEMALE & 42 & $27.50 \pm 11.89$ & \\
\hline \multirow{2}{*}{$\begin{array}{c}\text { AGE } \\
\text { (IN YEARS) }\end{array}$} & $<12$ & 25 & $30.37 \pm 12.74$ & \multirow{2}{*}{0.70} \\
\hline & $>12$ & 81 & $26.20 \pm 12.22$ & \\
\hline \multirow{2}{*}{$\begin{array}{c}\text { BMI } \\
\text { (IN KG/M2) }\end{array}$} & $<18$ & 45 & $26.89 \pm 11.42$ & \multirow{2}{*}{0.21} \\
\hline & $>18$ & 58 & $27.37 \pm 13.31$ & \\
\hline \multirow{2}{*}{$\begin{array}{l}\text { EXPERIENCE } \\
\text { (IN YEARS) }\end{array}$} & $<5$ & 49 & $26.96 \pm 10.32$ & \multirow{2}{*}{0.13} \\
\hline & $>5$ & 57 & $27.37 \pm 14.05$ & \\
\hline \multirow{2}{*}{ LEVEL } & AMATEUR & 39 & $27.34 \pm 9.66$ & \multirow{2}{*}{$0.047 *$} \\
\hline & PROFESSIONAL & 67 & $27.09 \pm 13.83$ & \\
\hline \multirow{2}{*}{ CURRENT PAIN } & YES & 26 & $27.99 \pm 12.23$ & \multirow{2}{*}{0.86} \\
\hline & NO & 80 & $26.92 \pm 12.53$ & \\
\hline \multirow{2}{*}{ CLICKS \& CATCHES IN PAST 1 YR } & YES & 25 & $28.05 \pm 12.48$ & \multirow{2}{*}{0.69} \\
\hline & NO & 81 & $26.92 \pm 12.46$ & \\
\hline
\end{tabular}

However, none of the variables showed a there was no significant difference in ellipse area and total stability index between the groups.

Table 3 highlights difference in anti-clockwise tracing error between groups. The groups did not differ significantly in terms of gender, BMI, experience in years, level at which they play, current pain, and clicks \& catches in the past 1 year. However, we did observe a significant difference in terms of age (Graph 1). 25 players were below the age of 12 while 81 were over 12 years of age. Mean anti-clockwise tracing error in of the 25 players below the age of 12 was $38.58 \pm 14.89 \%$ and of those of the 81 players above 12 years was $28.56 \pm 11.18 \%$. The significant difference was 0.03 .

Table 4 shows the difference in clockwise tracing error between groups. There was no significant difference observed in terms of gender, age, BMI, experience in years, current pain, and clicks \& catches in the past 1 year. We found a significant difference in the level at which they play (Graph 2). 39 players were playing at the amateur level whereas 67 were professional badminton players. Mean clockwise tracing error in of the 39 amateur players was $27.34 \pm 9.66 \%$ and of the 67 professional players was $27.09 \pm 13.83 \%$. The significant difference was 0.047 .

For gross stability data, Out On recording the gross data, out of the 106 athletes, $27 \%$ were 'poor', $47 \%$ had 'normal' static stability and $26 \%$ fell under the 'sportsperson' category (Chart 1). In terms of dynamic stability (Chart 2), 25\% were 'poor', $40 \%$ had 'normal' dynamic stability, while $35 \%$ were categorised as 'sportsperson'. On assessing pelvic stability, $15 \%$ were 'poor', $68 \%$ had 'normal' pelvic stability, and 18 were recorded found to be in the 'sportsperson' category (Chart 3).

As seen in table 3, there is a significant difference in Anti-clockwise tracing error between badminton players aged below and above 12 .

\section{Discussion}

Badminton is a dynamic equilibrium process which involves loss of balance in the air and restoration of balance after landing, and hence players need body coordination and dynamic balance [24]. In addition to moving back and forth on the court, players conduct various movement patterns during the game including twists, jumps, and swings to strike the shuttle-cock [25]. The game is characterized by a changing temporal structure, with actions of short period and high intensity coupled with short resting times [25]. Badminton requires specific physical conditioning in terms of action controls such as reaction time, foot stepping, and static or dynamic balances, which are essential motor demands in the sport [26]. Previous studies have highlighted the importance of stability in sport, and particularly in Badminton. 


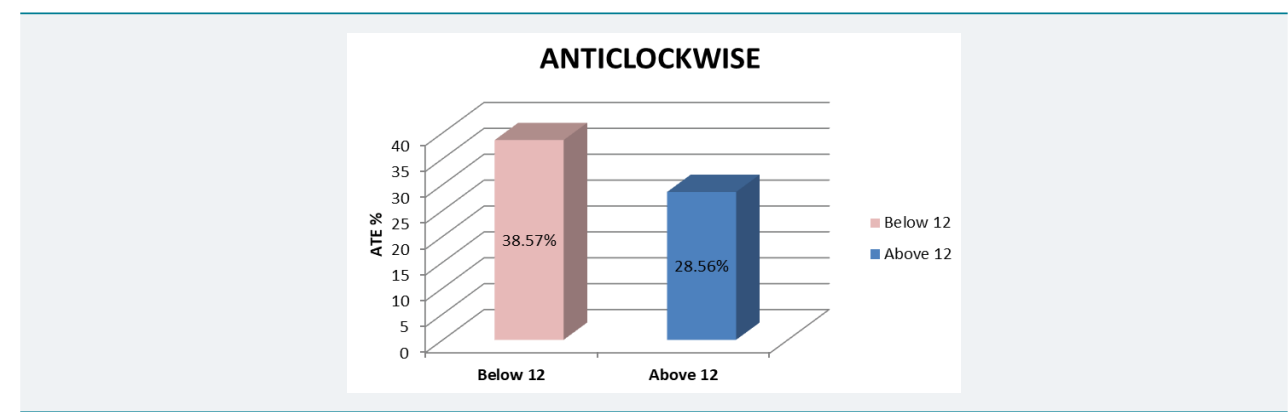

Graph 1: Significant difference (0.03) in Anti-clockwise tracing error between badminton players aged below and above 12 years.



Graph 2: Significant difference $(p=0.047)$ in Clockwise tracing error between amateur and professional badminton players
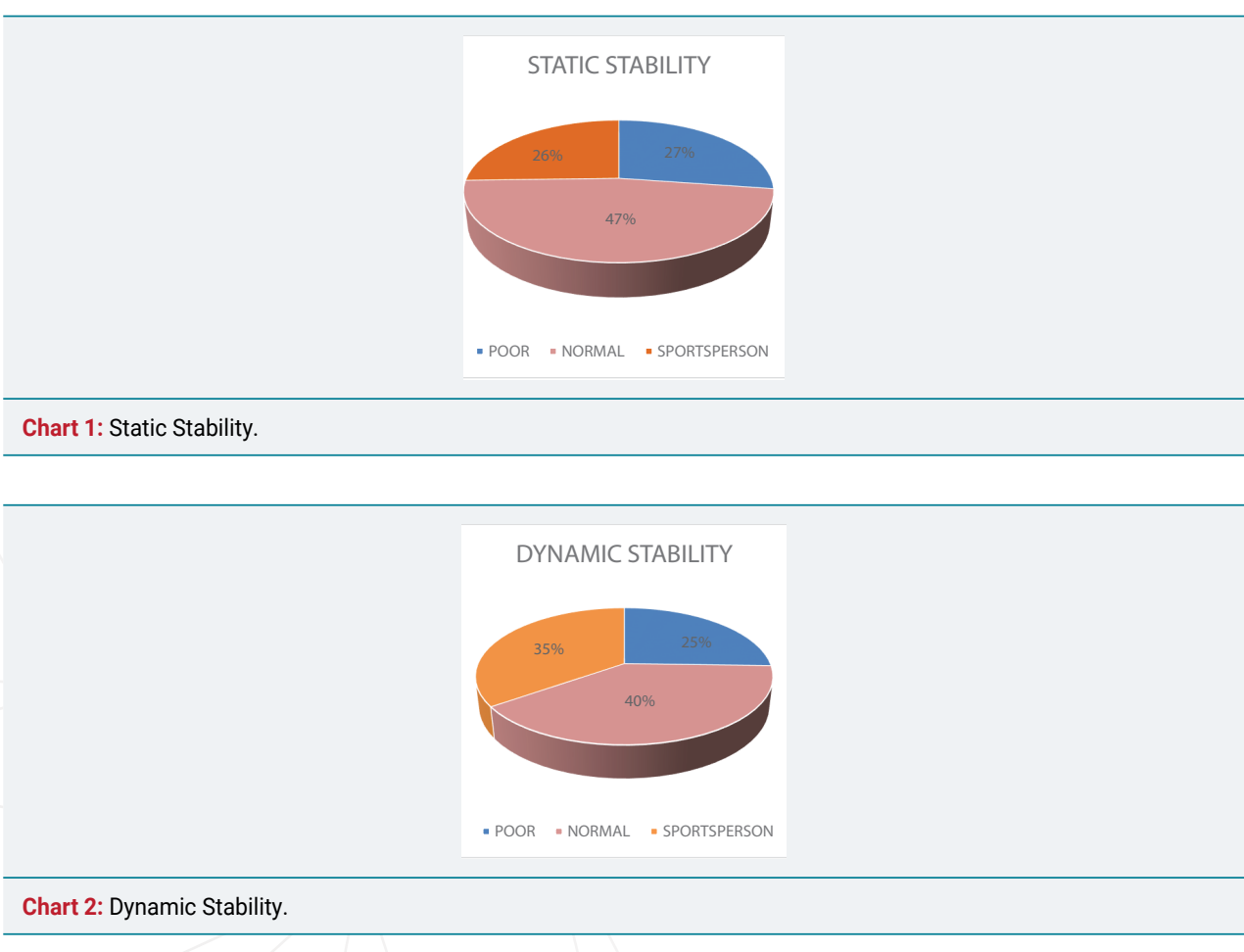

\begin{tabular}{ll}
\hline & PELVIC STABILITY \\
\hline Chart 3: Pelvic Stability. & POOR NORMAL $=$ SPORTSPERSON \\
\hline
\end{tabular}


Based on our results, we found that there is a significant difference in anti-clockwise tracing error between players aged below and above 12 . We also found a significant difference in clockwise tracing error between amateur and professional players. Rest of the variables proved did not prove to be significant with respect to ellipse area, total stability index, anti-clockwise and clockwise tracing error. The variables can be categorized into non-modifiable and modifiable factors. Non-modifiable factors include gender, age and years of experience. Modifiable factors include body mass index, level, current pains, and clicks and \& catches in the body.

\section{Non-modifiable variables}

There is no significant difference in stability between male and female players. There has been a study in which it was found that female athletes have higher trunk extensor endurance and lower flexor-to-extensor endurance than compared to male athletes [27]. Another study in the past has demonstrated that female athletes have lesser activity of the gluteus maximus muscle compared to their male counterparts, also making them more prone to injuries [28]. These findings may indicate that females find it more difficult controlling the hip during dynamic movement. However, in our study we did not find the difference to be significant. There is a significant difference between players below and above the age of 12 years in anti-clockwise tracing error (pelvic stability). A study has shown that those with more development of skeletal, musculature and adipose tissue in their bodies tend to have better motion exercise responses [29]. This supports our results that pelvic stability improves with age. However, there is no significant difference in static and dynamic stability between the two age groups. We compared groups having less and more than 5 years of playing experience and found that there was no significant difference present. This shows that despite players having more than 5 years' experience in the sport, they may not have access to specialists who can help train them in improving their stability or that stability is not being given the importance it needs.

\section{Modifiable variables}

On comparing body mass index of players, there was no significant difference found between those with a BMI of less than and above 18. A study on sexual dimorphism and its implications on performance showed that most of the differences in motion exercise responses come from differences in body size [29]. However, contrastingly, in our study, we did not find any such difference. There was a significant difference in clockwise tracing error (pelvic stability) between amateur and professional players. Previous studies have confirmed that efficient neuromuscular control of trunk stability and perfect trunk muscle recruitment patterns are vital factors for the control of spinal load in relation to position during the body's movement [30]. This could suggest that professional players are training on their trunk control, core stability and doing exercises to improve spinal load distribution, resulting in a superior pelvic stability compared to the amateur players. This also suggests that various changes occur in players as they become professional however the cross extension of these changes to static and dynamic stability is not evident. There may be a need for targeted interventions to improve static and dynamic stability as a player becomes professional. There was no significant difference between players who were in current pain and those who were painless and between those who had experienced clicks, cracks or catches in the past 1 year and those who had not.

As shown in the above charts, the percentage of athletes falling under the 'sportsperson' category is very less in terms of static, dynamic, and pelvic stability. Also, the large number under the 'poor' category is further proof that stability training is not being given the importance it deserves. In today's age of competitive sport, every player and coach is doing their level best to take the standard of play to the next level. Stability training needs to be incorporated in a player's regimen to help improve performance output. Whether the players do not have access to specialists 
who can give them this form of training or whether this form of training is not being given the importance it needs, is debatable. Either way, research has shown that it is an important factor in a player's development and performance, and that currently it is being neglected by junior and upcoming badminton players.

There were some limitations we faced in our study. Firstly, the participants included players between the ages of 8 and 15 years only. Secondly, one definitive test was performed for assessment of static, dynamic, and pelvic stability, whereas the machines have multiple tests for the assessment of each, which may allow for further analysis of data. Thirdly, the study could have included a wider geographical area including players from more Asian countries.

This study opens up new grounds for further research. Further studies can address other variables not included in the present study. Additionally, targeted interventions are needed to improve stability for players and the effect of such improvements on performance need to be determined.

\section{Conclusion}

This study shows that there is a significant difference in pelvic stability in terms of age and level at which players compete. Those above the age of 12 and professional players had better pelvic stability compared to players below 12 years and playing at the amateur level. However, no significant difference in static, dynamic and pelvic stability across other variables is a sign that stability not being given the importance it needs. Understanding its importance in overall improvement in athletic performance is a must and may help take their output to a whole new level.

\section{Acknowledgements}

We are grateful to the Badminton Association of India (BAI) for their permission in conducting this study. We thank Abhinav Bindra Targeting Performance and Padukone-Dravid Centre for Sports Excellence (CSE) for allowing us to conduct this study using the machinery in their facility. Image courtesy www.te cnobody.it and ABTP Centre, Bangalore.

\section{Ethics}

Institutional Ethics Committee approval for research into badminton players obtained from Fortis Hospital, Mohali Institutional Ethics Committee Board.

\section{References}

1. Guillain JY. Badminton: An Illustrated History Jean-Yves Guillain Publibook Anglais Broche. Retrieved August 24, 2018; Ref.: https://goo.gl/Lf913S

2. Mikkelsen F. Physical demands and muscle adaptation in elite badminton players, 1. Ref.: https://goo.gl/QuPgzL

3. Omosegaard B. Design of Training using Scientific Data - A Practical Approach as a National Coach, 13. Ref.: https://goo.gl/fqp5Ca

4. Sørensen K. A Biomechanical Analysis of Clear Strokes in Badminton Executed by Youth Players of Different Skill Levels, 2010; Ref.: https://goo.gl/rYrDPu

5. Waddell DB, Gowitzke BA. Biomechanical principles applied to badminton power strokes. ISBS Conference Proceedings Archive. 2000; 1. Ref.: https://goo.gl/ZBWyyj

6. Gowitzke BA, Waddell DB. Biomechanical studies of badminton underarm. Power strokes, court movement, and flexibility -- a review. 2018: Ref.: https://goo.gl/Lc92SS

7. Yang Y. Research of badminton forehand smash technology based on biomechanical analysis. Journal of Chemical and Pharmaceutical Research. 2014; 6: 962-969. Ref.: https://goo.gl/Wfb86x

8. Xiang Liu, Kim W, Tan J. Badminton Smash | Anatomical Terms Of Motion | Rotation Around A Fixed Axis. 2018; Ref.: https://goo.gl/HsMHyT 
9. Hassan I. The Effect of Core Stability Training on Dynamic Balance and Smash Stroke Performance in Badminton Players. 2017 2: Ref.: https://goo.gl/Up5MZe

10. Tsai CL, Chang SS. Biomechanical analysis of emg activity between badminton smash and drop shot. 1. Ref.: https://goo.gl/9JJKBP

11. Sakurai S, Ohtsuki T. Muscle activity and accuracy of performance of the smash stroke in badminton with reference to skill and practice. J Sports Sci. 2000; 18: 901-914. Ref.: https://goo.gl/94m9h3

12. Wonisch M, Hofmann P, Schwaberger G, von Duvillard SP, Klein W. Validation of a field test for the non-invasive determination of badminton specific aerobic performance. Br J Sports Med. 2013; 37: 115-118. Ref.: https://goo.gl/UZ7THJ

13. Andersen L, Larsson B, Overgaard H, Aagaard P. Torque - Velocity characteristics and contractile rate of force development in elite badminton players. Eur J Sport Sci. 2007: 7: 127-134. Ref.: https://goo.gl/MNTaoP

14. Faccini P, Dai Monte A. Physiologic demands of badminton match play. Am J Sports Med. 1996; 24(6 Suppl): S64-66. Ref.: https://goo.gl/dyjzp8

15. Faude O, Meyer T, Rosenberger F, Fries M, Huber G, et al. Physiological characteristics of badminton match play. Eur J Appl Physiol. 2007; 100: 479-485. Ref.: https://goo.gl/b56YCT

16. Ooi CH, Tan A, Ahmad A, Kwong KW, Sompong R, et al. Physiological characteristics of elite and subelite badminton players. J Sports Sci. 2009; 27: 1591-1599. Ref.: https://goo.gl/Njw8mP

17. Høy K, Lindblad BE, Terkelsen CJ, Helleland HE, Terkelsen CJ. Badminton injuries--a prospective epidemiological and socioeconomic study. $\mathrm{Br} J$ Sports Med. 1994; 28: 276-279. Ref.: https://goo.gl/m1RMdL

18. Goh SL, Mokhtar AH, Mohamad Ali MR. Badminton injuries in youth competitive players. J Sports Med Phys Fitness. 2013; 53: 65-70. Ref.: https://goo.gl/PP2g9n

19. Hensley LD, Paup DC. A survey of badminton injuries. Br J Sports Med. 1979; 13: 156-160. Ref.: https://goo.gl/ur2nP4

20. Fahlström M, Yeap JS, Alfredson H, Söderman K. Shoulder pain -- a common problem in world-class badminton players. Scandinavian Scand J Med Sci Sports. 2006; 16: 168-173. Ref.: https://goo.gl/u3CCSU

21. Jørgensen U, Winge S. Injuries in badminton. Sports Med. 1990; 10: 59-64. Ref.: https://goo.gl/LTKNUU

22. Krøner K, Schmidt SA, Nielsen AB, Yde J, Jakobsen BW, et al. Badminton injuries. Br J Sports Med. 24: 169-172. Ref.: https://goo.gl/zZRaVG

23. Bressel E, Yonker JC, Kras J, Heath EM. Comparison of static and dynamic balance in female collegiate soccer, basketball, and gymnastics athletes. J Athl Train. 42; 42-46. Ref.: https://goo.gl/Bxj2Yc

24. Ming-Min K, Qing L. The Interpretation of Functional Training and Its Application in Badminton. 2013; Ref.: https://goo.gl/9G4c1n

25. Phomsoupha M, Laffaye G. The science of badminton: game characteristics, anthropometry, physiology, visual fitness and biomechanics. Sports Med. 2015; 45: 473-495. Ref.: https://goo.gl/as5wJL

26. Laffaye G, Phomsoupha M, Dor F. Changes in the Game Characteristics of a Badminton Match: A Longitudinal Study through the Olympic Game Finals Analysis in Men's Singles. J Sports Sci Med. 14: 584-590. Ref.: https://goo.gl/e7vF2Z

27. Nikolaidis P. Core stability of male and female football players. 2010; $2: 30-33$. Ref.: https://goo.gl/hWwkcw

28. Zazulak BT, Ponce PL, Straub SJ, Medvecky MJ, Avedisian L, et al. Gender Comparison of Hip Muscle Activity During Single-Leg Landing. J Orthop Sports Phys Ther. 35; 292-299. Ref.: https://goo.gl/CwGNEM

29. Rivas RC, Andries Junior O. Sexual dimorphism and its implications on the performance and planning of women's sports. Mov Percep. 2007; 7: 126-148. Ref.: https://goo.gl/otxiZT

30. Granata KP, England SA. Stability of Dynamic Trunk Movement. Spine (Phila Pa 1976) 2006;. 31 E271-E276. Ref.: https://goo.gl/1Ghw2n 